\title{
Global warming: Facing confirmation bias and cognitive dissonance with hands-on activities
}

\author{
Leontýna Šlégrová, Jan Šlégr, Filip Studnička \\ University of Hradec Králové, Czech Republic
}

\begin{abstract}
Although global warming is an irrefutable scientific fact, many people, including those who often call themselves skeptics and critical thinkers, are doubtful about this unambiguous fact. An extensive longitudinal survey amongst the students showed that even future teachers are not resistant to these misconceptions, even if they are presented with the conclusions of the scientific studies.

In this paper, we show simple hands-on classroom activities in which publicly available climate data are studied with methods previously known to students, and simple atmospheric models are presented. These simple exercises can help future teachers to establish their own opinion on global warming based on the analysis of data and physical models and not on information from obscure websites and social networks.
\end{abstract}

Keywords: global warming, hands-on activities, cognitive bias

This is an open access article under the CC-BY-NC license.

\section{INTRODUCTION}

The topic of Global Warming has recently resonated not only on the Internet (Global Climate Scam, 2017), which is the breeding ground for various conspiracy theories but also in the media (The word is getting warmer, 2019). Perceptions of global warming and climate change risks is an interesting psychological phenomenon, which is currently under study (Psychology and Global Climate Change, 2009).

People often base their views, not on a rational assessment of objective data and arguments - many other things play a role in their decision making, for example, the opinions that are common in their social group. These ways of decision-making are called "group dynamics" or "tribal instincts." (Boyd and Richerson, 2001)

Many people do not believe in global warming at all, or they have an opinion that the temperatures are not rising because of human actions but are only fluctuating as part of a larger natural cycle.

More than one-quarter of Americans are climate change skeptics (Gallup, 2015), even though Cook et al. (Cook, 2013) found that over $97 \%$ of scientific papers he surveyed endorsed the view that the Earth is warming up. Human emissions of greenhouse gases are the primary cause.

This says a lot about how the public perceives science. The opinions of experts, scientists, and teachers are nowadays not more reliable than information found on obscure websites.

According to Festinger (Festinger and Carlsmith, 1959), the individual responds to tensions caused by two mutually inconsistent attitudes by trying to add, remove, or change his or her cognitive structures. 
Cognitive dissonance is a state of mind that arises from a contradiction between two cognitions, for example, between attitudes (knowledge, faith, behavior) and the real state of matter. This is why many people are trying to reject the idea of global warming with a variety of dubious explanations. People also tend to think that they are smarter than the media. However, the media are bound by codes that require them to publish verified information from several sources and to be in line with science and technology. In contrast, people on social networks are exchanging meaningless, made-up information, sometimes even maliciously. Then they think that this is the same thing as listening, reading, or looking at solid media with proven data. In this article, we present some simple hands-on activities that can be used in teacher training.

\section{SURVEY RESULTS}

An extensive longitudinal study was designed, and the on-line questionnaire was distributed to undergraduate students at a faculty of education (preparing teachers of humanities and for primary schools) and at a faculty of science (preparing teachers of science for primary and secondary schools).

From the total number of people who filled the questionnaire $(\mathrm{N}=264), 97.3 \%$ regard themselves as critical thinkers, and $63.5 \%$ would call themselves skeptics.

In the next part of the questionnaire, the students were asked for their opinion on different topics, including astrology, evolution theory, Flat Earth theory, homeopathy, and global warming.

It should be noted that $78.9 \%$ of respondents believe in global warming, which we consider a decent result. Meanwhile, $6.3 \%$ do not know, or they do not have any opinion. Further analysis of the remaining $14.8 \%$ showed two groups of answers: There are two equally large groups of students, one in humanities teacher training (mostly history, social sciences, and PE) and one studying sciences (mathematics, biology, and ICT).

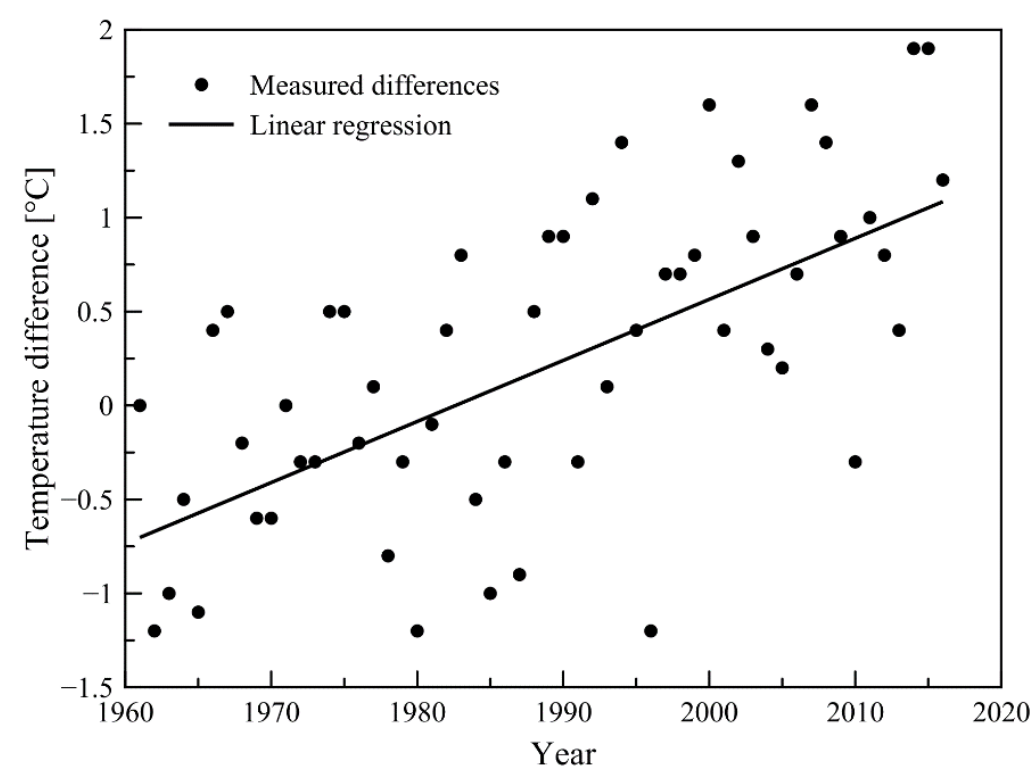

Figure 1. Measured yearly temperature differences and linear regression.

Because the survey was anonymous, we can only make a qualified estimate that the opinion of the humanities teachers' group is formed mainly by media and hoax websites. Still, in the case of the science teacher's group, there is also the Dunning-Kruger effect in play. This is a well-known example of cognitive bias examined by social psychology, wherein people of low ability in a particular field suffer from illusory superiority, mistakenly assessing their cognitive ability as more significant than it is. 


\section{HANDS-ON DATA ANALYSIS ACTIVITIES}

We have learned that the best activities to prove a point and fight confirmation bias are hands-on ones. This is the reason why we designed a set of such activities where students have to analyze real data and see for themselves that the recent changes in temperatures are not random and that the most likely cause is anthropogenic.

Even if students would consider global warming as a worldwide conspiracy of the ruling elites (Jeffrey, n.d.), it is unlikely that the local meteorological site will also take part in this plot. For this reason, a time series of average local annual temperatures were selected for the initial analysis (see Fig. 1).

\section{The most straightforward approach: Temperature correlation}

Simple analysis can be performed by calculating Pearson's correlation coefficient, which measures the strength of the linear relationship between two variables. For example, it can help us quantify how strong the link between results is in two different tests. In this case, $R=0.6438$. For the hypothesis that the temperature differences are not linearly correlated with time (time series consisting of the years), it is

$$
\frac{R}{\sqrt{1-R^{2}}} \sqrt{N-2}=6.1727
$$

The critical value is 2.0048, so we refute the hypothesis that these two data sets are not correlated and because $R>0$, we can say that the temperature is indeed rising. If the students did not undergo statistics training, the same conclusion could be drawn from linear regression, although there are significant differences from year to year.

\section{Atmospheric sensitivity to $\mathrm{CO}_{2}$}

After this straightforward exercise, we can proceed to more advanced ones. Data are taken from the website (Roston and Migliozzi, 2015), which is a good graphical representation that draws a comparison between the global land and ocean temperature record, as measured by NASA's Goddard Institute for Space Studies (GISS) (GISS Surface Temperatura Analysis, n.d.) and modeled estimates that each climate factor contributes to the overall temperature. The computer model that generated the results for this graphic is ModelE2 (Miller, 2012).

Raw data can be downloaded from the website (Roston and Migliozzi, 2015), and several scatter plots can be created by students. From Fig. 2, one can clearly see that the temperature rise is not correlated with changes in the Earths' orbit, the Sun's power output, volcanic activity, or these three things combined.

From Fig. 2(d), the strong correlation of temperature variations and the influence of greenhouse gases on model output is apparent. The Pearson correlation coefficient can be calculated, yielding in this case result of $R=0.9046$. Taking into account 126 paired samples, this effect is significant at $p<0.01$. 

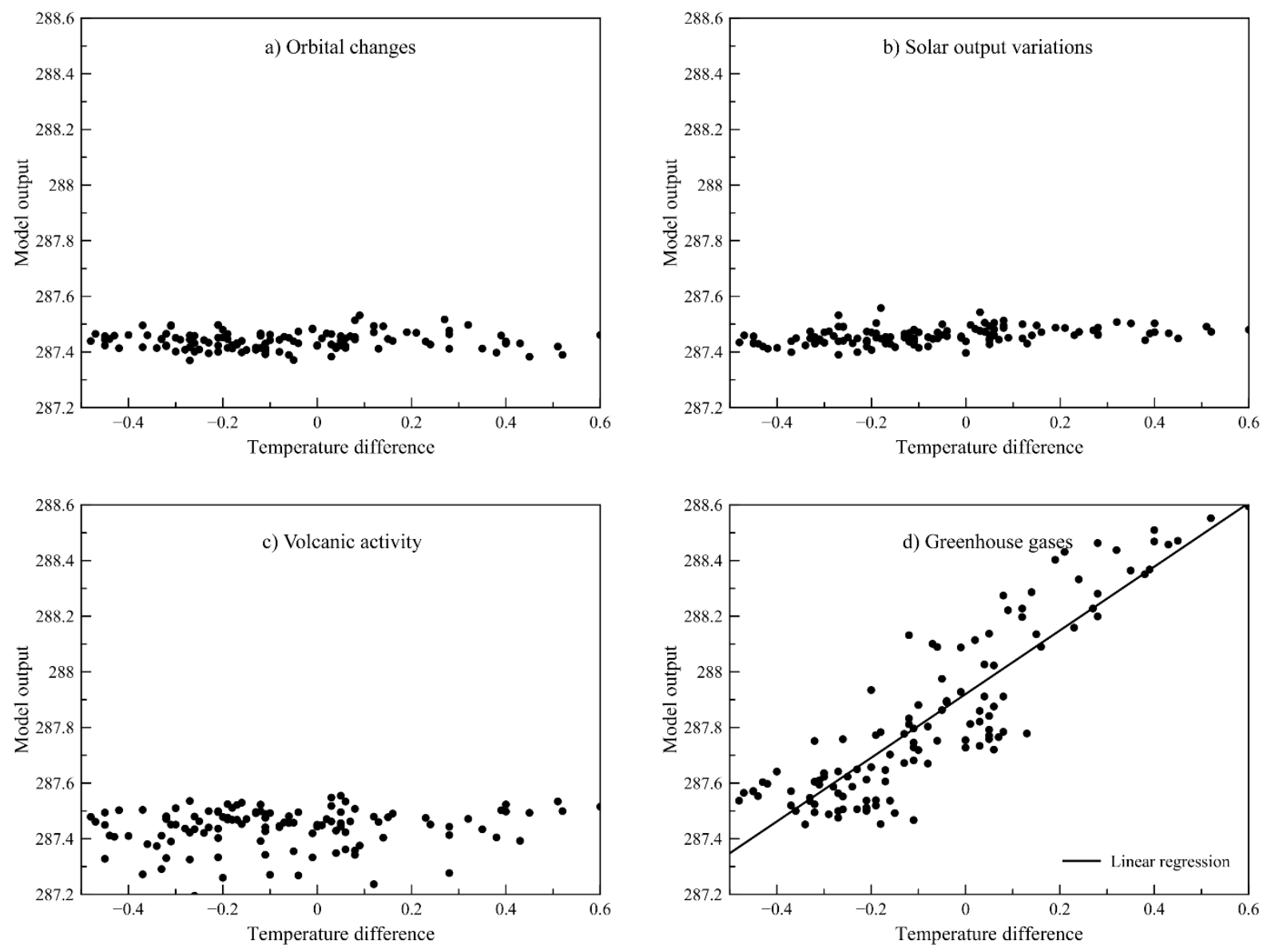

Figure 2. Atmospheric sensitivity to various influences

\section{Climate change as a random variation}

Climate change is influenced by so many complicating factors that skeptics could say that the rise in temperature can be explained by some random variation. In this part, we would like to introduce a simple model based on the random walk that will be compared with real temperature data from the Czech Republic. We will make several iterations of this model and will try to find whether the temperature rise in the Czech Republic can be easily explained using random variations.

The average year temperature varies from year to year, but it should not be absolutely independent. The soil, water, and air act as a heat accumulator, so it is natural to see that temperature change is dependent on the temperatures in the previous years.

The model we will use is based on two ideas. First, we can assume that the temperature varies from year to year with some random error; that is, temperature $T_{i}$ in the year can be calculated as $T_{i}=\bar{T}+E_{i}$ where $\bar{T}$ is mean temperature and $E_{i}$ is normally distributed with $N\left(0, \sigma^{2}\right)$. This model is known as a random walk, and it is used, for example, to model the movement of molecules in the air. This part will give us insight into random changes. However, this model does not incorporate the dependencies on previous years, and it does not produce runs of warm or cold years, which can be observed in real data. We extend this model to be regressive, and the temperature $T_{i}$ is calculated as follows:

$$
T_{(i+1)}=\alpha+\beta T_{i}+E_{i},
$$

where $T_{1}$ is taken as a starting temperature in the year 1961. Parameter $\beta<1$ is a factor that tells us how strong the dependency is on the previous years' temperature, and $\alpha$ acts as an offset of changes in 
year-to-year temperatures. To find the values of parameters $\alpha$ and $\beta$, let us look at the plot of $T_{(i+1)}$ over $T_{i}$. To do so, we create two vectors, one with temperatures from the years 1962-2016 and one with temperatures from the years 1961-2015. If we plot these temperatures against each other, we obtain Figure 3.

We can now use linear regression to estimate the values of parameters $\alpha$ and $\beta$. For data from the Czech Republic, we obtained $\alpha=4.437$ and $\beta=0.4285$. The last parameter that we need to calculate in our model is the variance $\sigma^{2}$. This can be done easily if we realize that it is just the variance of the random variable $E_{i}=T_{(i+1)}-\alpha-\beta T_{i}$. We obtain a value of $\sigma^{2}=0.565$. This model is sufficient to produce similar data to that found in the real temperature in the world (see Fig. 4).

We have performed 1,000,000 calculations of our model. The point is to look at the potential changes in temperature due to the random process. We calculate differences in temperature from the average temperature for each year. The real data show that the correlation coefficient of temperature differences is $R=0.644$. We calculated this correlation coefficient for each output of our model and the mean correlation coefficient $\bar{R}=-0.0469$ with the square root of variance $\sigma_{m}=0.2003$. The correlation coefficient $R$ lies more than $3 \sigma_{m}$ from the mean value, which proves that it is highly improbable for the measured temperature to be just a random process without any external influences.

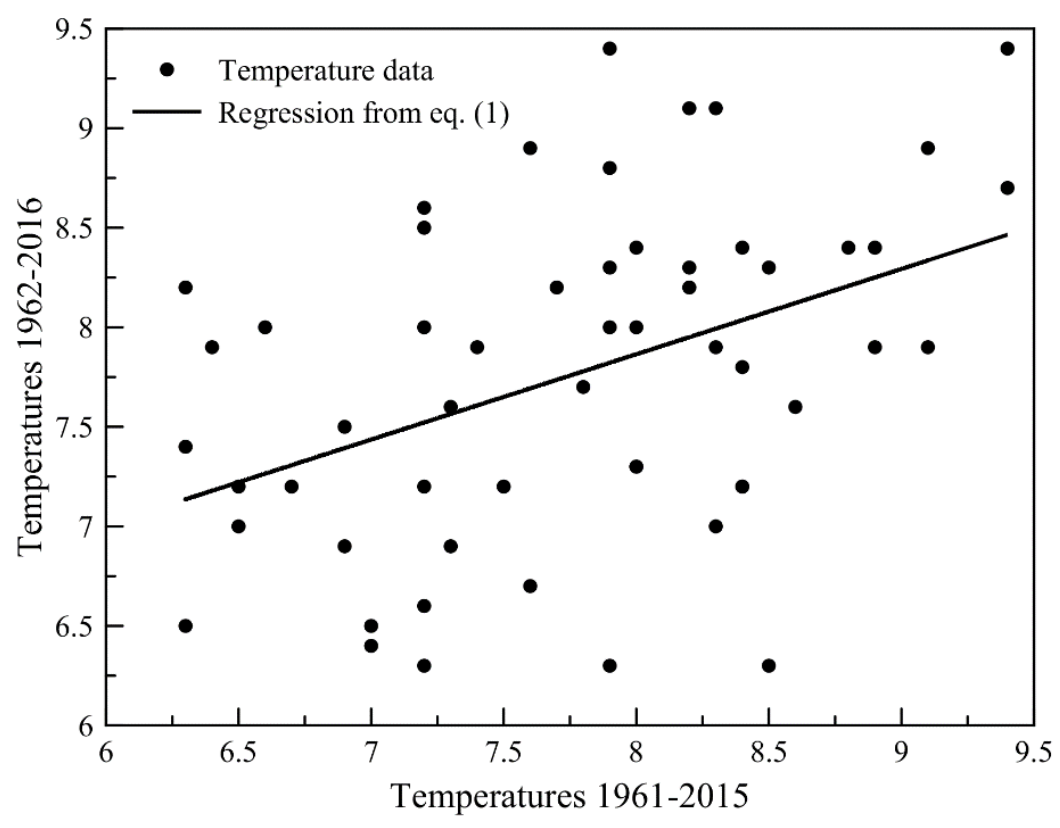

Figure 3. Temperatures from years 1962-2016 over temperatures from years 1961-2015 
International Journal of Research in STEM Education (IJRSE), Vol. 2 (2), 123-133

Global warming: Facing confirmation bias and cognitive dissonance with hands-on activities

Leontýna Šlégrová, Jan Šlégr, Filip Studnička

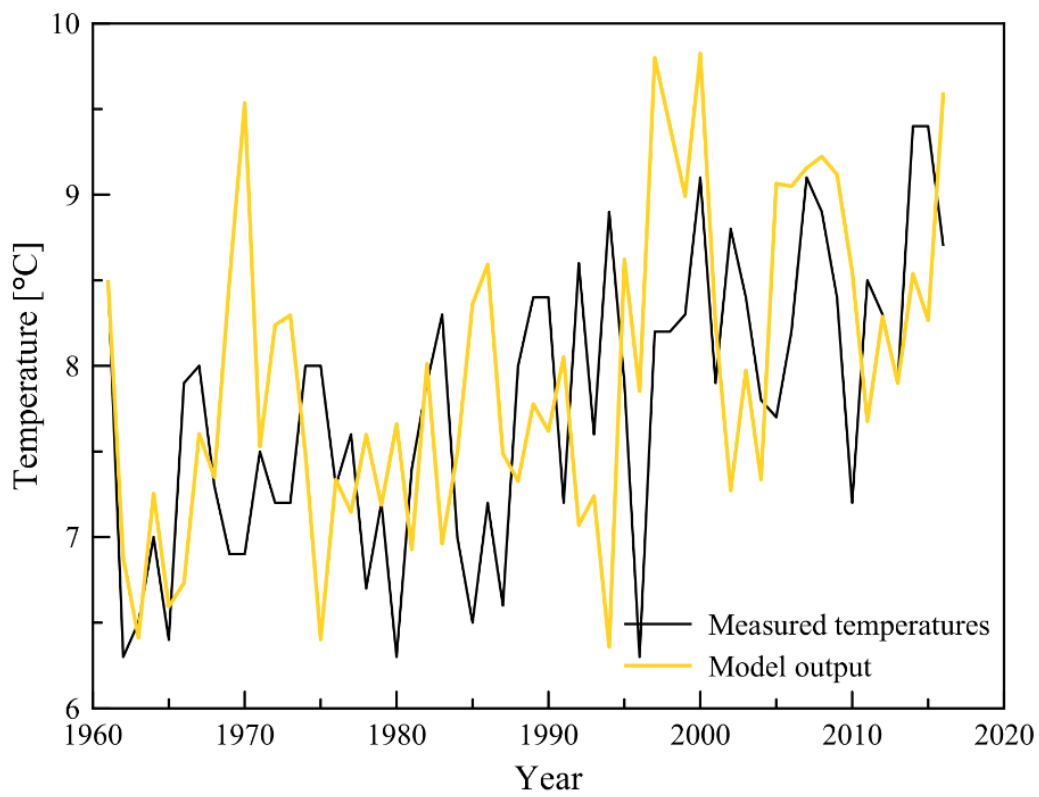

Figure 4. One output from the random walk model

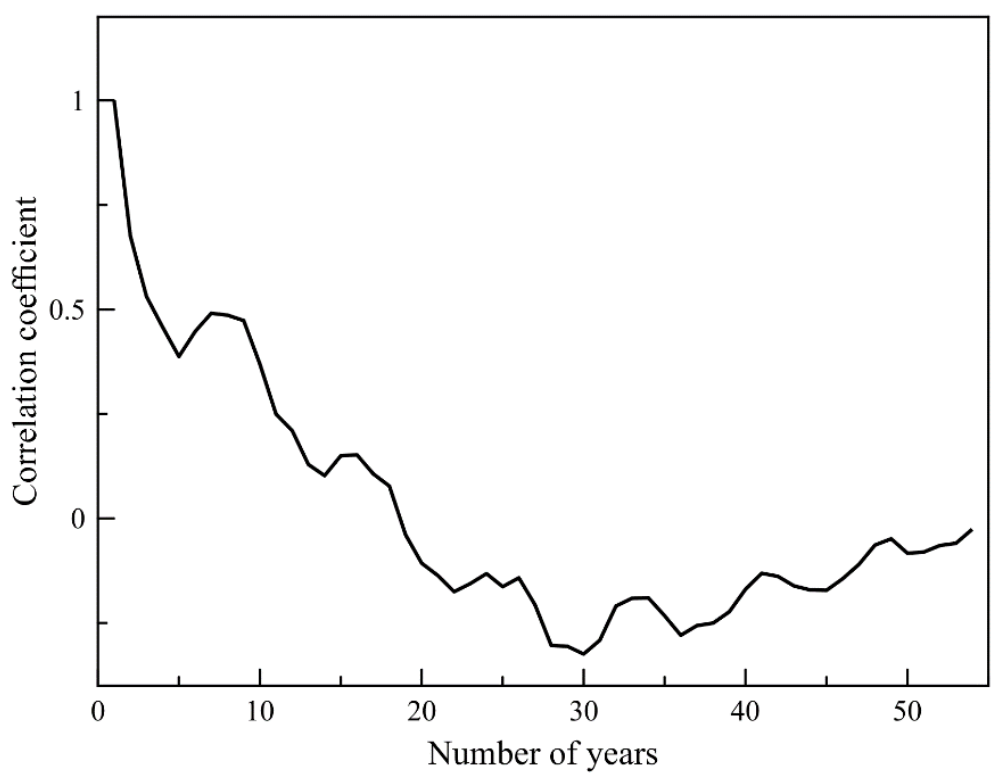

Figure 5. Correlation coefficient vs year lag. 


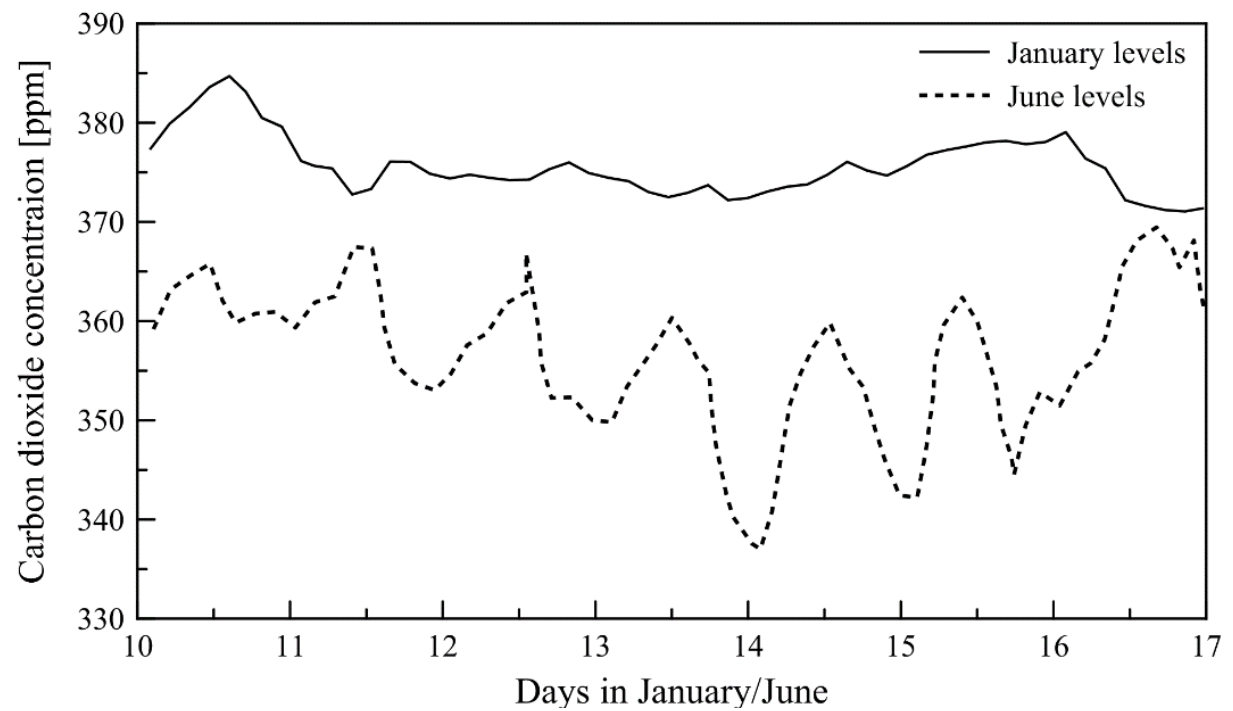

Figure 6. $\mathbf{C O}_{2}$ levels measured during summer and winter.

\section{Relatedness of temperature on previous years}

It is possible to calculate the amount of relatedness of changes in temperatures to previous years. This model is intended for more advanced courses because we calculate the cross-correlation function of changes in temperatures between the years 1961-2015 and 1962-2016. This cross-correlation function tells us how many years back, we should look at more rigorous models of temperature change. The result is given in Figure 5. The $x$-axis shows the number of years lag, and the $y$-axis shows the correlation coefficient between the actual year and lag years. The first point gives us a correlation coefficient because it is the correlation between the year itself. The correlation then slowly tails off. The most interesting part is the oscillation with periodicity at around nine years. This means that the changes in temperature show some regularity. The exact period can be calculated using an autocorrelation function of this crosscorrelation.

This interesting finding is in correspondence with (Kożuchowski, Trepińaska, Wibig, 1994), where a similar periodicity was found in temperature data from a station near Kraków, Poland, which lies on similar global coordinates as the Czech Republic (Kraków lies less than $100 \mathrm{~km}$ from the Czech Republic), which means that it has a very similar climate. This was explained as a result of the central European climate oscillations, and our finding proves this hypothesis.

\section{Local $\mathrm{CO}_{2}$ data}

The last objection can be pointed to $\mathrm{CO}_{2}$ measurement. Mauna Loa is a remote location, and students have to justify the fact that $\mathrm{CO}_{2}$ values are measured in such remote areas. If there is a weather station at the college, then data analysis can be performed as follows:

Fig. 5 shows local $\mathrm{CO}_{2}$ levels in July with a dashed line. There is a very large diurnal cycle-at sunset when photosynthesis shuts down and the $\mathrm{CO}_{2}$ concentration increases because plants keep respiring during day and night, releasing $\mathrm{CO}_{2}$. During the day, photosynthesis is stronger than respiration, which causes the removal of $\mathrm{CO}_{2}$ from the atmosphere. During the night, the ground cools, and the atmosphere becomes stable. The respired $\mathrm{CO}_{2}$ is then trapped in the stable boundary layer near the ground, which may have a thickness of tens of meters. The build-up of respiratory $\mathrm{CO}_{2}$ near the ground is more strongly dependent on the atmospheric stability, driven by the weather, than on the rate of respiration. The 
weather dependency is very easy to see from a comparison of winter and summer data (Fig. 6 shows data from January with a thick line). This is the reason why background sites like Mauna Loa are used, which average over vast areas.

\section{SIMPLE MODELS OF ENERGY DISTRIBUTION}

These simple models can be beneficial for students who are not taking a major in meteorology, climatology, or geophysics, especially for future science teachers.

Taking into account solar luminosity $L_{\odot}=3.828 \cdot 10^{26} \mathrm{~W}$, in the distance of one astronomical unit $d \cong 149.6 \cdot 10^{9} \mathrm{~m}$, we have flux density.

$$
I_{C S}=\frac{L_{\odot}}{4 \pi d^{2}} \cong 1361 \mathrm{~W} \cdot \mathrm{m}^{-2} \text {. }
$$

While the solar rays can be considered to be parallel, we have to take into account the dependence of the amount of incident sunlight on the geographical latitude. It can be shown that for the half-sphere $\left(S=\frac{1}{2} 4 \pi R_{E}^{2}\right)$ irradiated by the solar rays effective area is $S^{\prime}=\pi R_{E}^{2}$. For an ideal black-body, the incoming radiation absorbed by the Earth has to be balanced by the total flux radiated to space:

$$
\pi R_{E}^{2} I_{C S}=4 \pi R_{E}^{2} T^{4} \text {. }
$$

For the Earth system, $3 \%$ of insolation is scattered into space, $19 \%$ is reflected into space by clouds, and $9 \%$ is reflected into space by the ground surface. The surface albedo (as a measure of how much radiation is reflected back to space) for Earth is $\alpha \cong 0.3$. Taking this into account, we have

$$
\pi R_{E}^{2}(1-\alpha) I_{C S}=4 \pi R_{E}^{2} T^{4} \Rightarrow T=\sqrt[4]{\frac{(1-\alpha) I_{C S}}{4 \sigma}} .
$$

Note that the radius of the Earth, $R_{E}$, has canceled out: $T_{e}$ depends only on albedo and the distance of the Earth from the Sun. Putting in numbers, we find that the Earth has an effective temperature of 255 $\mathrm{K}$ or $-18^{\circ} \mathrm{C}$. The globally averaged observed surface temperature is $T_{s}=288 \mathrm{~K} \cong 15^{\circ} \mathrm{C}$, so other phenomena have to play a role in climate forming. Because the planet is in radiative equilibrium, there has to be an upward surface flux of infra-red radiation (about $\sigma T_{s}^{4} \cong 390 \mathrm{~W} \cdot \mathrm{m}^{-2}$ ), while the outward flux at the top of the atmosphere is roughly equivalent to the net solar radiation coming in $\left(\frac{1}{4}(1-\alpha) I_{C S} \cong\right.$ $240 \mathrm{~W} \cdot \mathrm{m}^{-2}$ ) Thus, a large amount of infra-red radiation is absorbed by the atmosphere (around $150 \mathrm{~W}$. $\mathrm{m}^{-2}$ ), this number would be zero in the absence of any greenhouse substances.

A very simple greenhouse model is depicted in Fig. 7. The energy flux balances are

Ground: $\quad \frac{(1-\alpha) I_{C S}}{4}=\varepsilon I_{A}$,

Atmosphere: $\quad \varepsilon I_{G}=2 \varepsilon I_{A}$,

Planet: $\quad \frac{(1-\alpha) I_{C S}}{4}=\varepsilon I_{A}+(1-\alpha) I_{G}$,

where $\varepsilon$ is the emissivity of the atmosphere. For a reasonable temperature, we can find $\varepsilon=0.78$. Solving for $I_{G}$, we get

$$
I_{G}=\sigma T_{S}^{4}=\frac{(1-\alpha) I_{C S}}{4 \sigma\left(1-\frac{\varepsilon}{2}\right)} \Rightarrow T=\sqrt[4]{\frac{(1-\alpha) I_{C S}}{4 \sigma\left(1-\frac{\varepsilon}{2}\right)}} .
$$

For $I_{C S}=1361 \mathrm{~W} \cdot \mathrm{m}^{-2}, \alpha \cong 0.3$, and $\varepsilon=0.78$, we get $T_{s}=288 \mathrm{~K} \cong 15^{\circ} \mathrm{C}$, which is a good agreement with the observed temperature. 


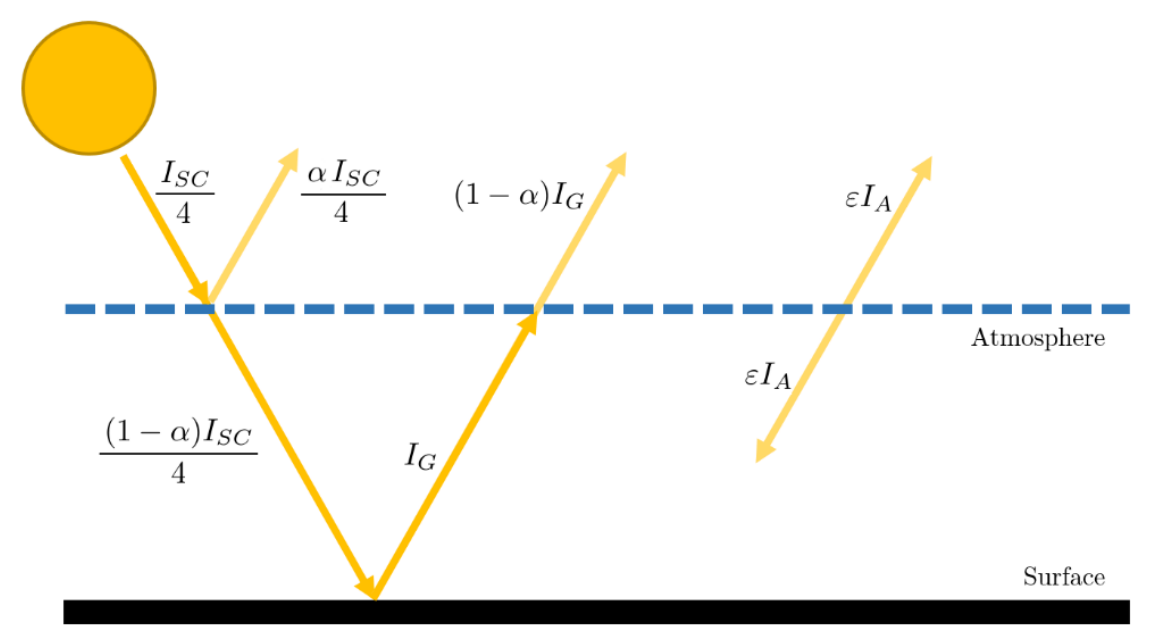

Figure 7. A simple linear model of energy distribution.

Global temperature changes when either $I_{C S}$ or $\varepsilon$ changes. These changes are usually both denoted as radiative forcing-whether from the Sun or from greenhouse gases, it has the same effect regardless of where it comes from. A more rigorous explanation can be found in (Radiative Forcing, 2015).

The radiative forcing for a doubling of $\mathrm{CO}_{2}$ is about $3.7 \pm 0.4 \mathrm{~W} \cdot \mathrm{m}^{-2}$, which is the same order of magnitude as an increase of solar forcing by $2 \%$ (Hansen, 2005). In that case, we can easily calculate that surface temperature will increase by $\Delta T_{s} \cong 1.5^{\circ} \mathrm{C}$.

While this is a straightforward model, it illustrates some relevant points that are just as qualitatively true for global climate models and the real world. However, it should be noted that other radiative forcings, albedo changes, and feedbacks, especially from increasing water vapor, also occur. The effects of both positive and negative feedback factors have to be accounted for in determining the climate's sensitivity associated with an increase in atmospheric $\mathrm{CO}_{2}$. This is the reason why climate models predict temperature increases in a range from 0.2 to $5^{\circ} \mathrm{C} \mathrm{per} \mathrm{W} \cdot \mathrm{m}^{-2}$ of radiative forcing. More details, still within reach of undergraduate science students, can be found in (Climate Sensitivity, 2013). Many other simple models are available; for example, in (Specht, Redemann, Lorenz, 2016), the atmosphere is modeled as a parallel combination of heat resistivities, and it is treated as a resistor net. These models neglect zonal flows. McGuffie and Henderson-Sellers present an interactive and relatively simple one-dimensional Earth zonal balance model (Welcome to Energy Balance Modeling!, 1998).

\section{CONCLUSIONS}

After the students had completed these exercises during five study sessions, a quick survey was conducted on whether this activity would change their view of global warming. The vast majority of them responded positively, and, in their opinion, this exercise could convince other climatic skeptics.

We believe that these straightforward exercises can contribute to the development of the students' critical thinking. What needs to be accentuated in schools is that the students should learn how to work with information. They should be shown to authenticate their sources, not to believe false information, and, of course, to be able to admit if they are wrong. There is a lot of news coming from the Internet and social media, and it is easy to find "information" that is in accordance with our biases. Right before our eyes, a generation has grown up flooded by information, and nobody is teaching them how to orient themselves in this vast ocean of data.

Nowadays, more than ever, it is essential to encourage students to learn critical and skeptical thinking and to adopt methods to help distinguish between ideas that are considered valid science and those that can be regarded as pseudoscience. Alongside almost classic publications (Sagan, 1995), 
(Mackay, 1841), (Williams, 2000), activities such as the rigorous deconstruction of specific arguments of presented pseudoscientific theory can be beneficial for students.

We also encourage other tutors to try out similar exercises in their lessons and publish their results or publish other ideas for expansion.

\section{ACKNOWLEDGMENTS}

This work was supported by the SV PřF UHK nr. 2103/2018.

\section{REFERENCES}

BOYD, Robert, RICHERSON, Peter J. The evolution of subjective commitment to groups: A tribal instincts hypothesis. In: Evolution and the Capacity for Commitment 3 (2001): 186-220.

Climate Sensitivity. (2013). Retrieved March 18, 2020, from https://www.acs.org/content/acs/en/climatescience/atmosphericwarming/climatsensitivity.h tml

COOK, John et al. Quantifying the consensus on anthropogenic global warming in the scientific literature. In Environ. Res. Lett. 8 (2013) 024024 (7pp). DOI:10.1088/1748-9326/8/2/024024

FESTINGERF, Leon; Carlsmith, James M. Cognitive consequences of forced compliance. In The Journal of Abnormal and Social Psychology,58(2), Mar 1959, 203-210.

GALLUP, Inc. (2015, March 25). In U.S., Concern About Environmental Threats Eases. Retrieved March 18, 2018, from http://news.gallup.com/poll/182105/concern-environmental-threatseases.aspx

GISS Surface Temperature Analysis (n.d.). Retrieved March 18, 2020, from https://data.giss.nasa.gov/gistemp/.

Global Climate Scam. (2017). Retrieved March 18, 2018, from http://www.globalclimatescam.com/

HANSEN, J. (2005). Earths Energy Imbalance: Confirmation and Implications. In Science, 308(5727), 1431-1435. doi:10.1126/science.1110252

JEFFREY, Grant, R.: The Global-Warming Deception: How a Secret Elite Plans to Bankrupt America and Steal Your Freedom. Retrieved March 18, 2018, from https://www.amazon.com/Global-Warming-Deception-Bankrupt-America-Freedom/.

KOŻUCHOWSKI, K., TREPIŃASKA, J., WIBIG, J. (1994). The air temperature in Cracow from 1826 to 1990: Persistence, fluctuations and the urban effect. In International Journal of Climatology, 14(9), 1035-1049. DOI:10.1002/joc.3370140908

MACKAY, Charles (1841). Memoirs of Extraordinary Popular Delusions and the Madness of Crowds. I (1 ed.). London: Richard Bentley.

MILLER, Ron R et al. CMIP5 historical simulations (1850-2012) with GISS ModelE2 https://pubs.giss.nasa.gov/abs/mi08910y.html.

Psychology and Global Climate Change: Addressing a Multi-faceted Phenomenon and Set of Challenges (Report of the American Psychological Association Task Force on the Interface Between Psychology and Global Climate Change, 2009)

Radiative Forcing. (2015). Retrieved March 18, 2020, from https://www.acs.org/content/acs/en/climatescience/atmosphericwarming/radiativeforcing.ht $\mathrm{ml}$

ROSTON, E., MIGLIOZZI, B. (2015, June 24). What's Really Warming the World? Retrieved March 18, 2020, from https://www.bloomberg.com/graphics/2015-whats-warming-theworld/.

SAGAN, Carl (1995). The Demon-Haunted World: Science As a Candle in the Dark. Random House. ISBN 0-394-53512-X.

SPECHT, E., REDEMANN, T., LORENZ, N. (2016). Simplified mathematical model for calculating global warming through anthropogenic $\mathrm{CO}_{2}$. In International Journal of Thermal Sciences, 102, 1-8. doi:10.1016/j.ijthermalsci.2015.10.039 
The world is getting warmer. (2019). Retrieved March 18, 2020, from https://www.nationalgeographic.com/environment/climate-change/

Welcome to Energy Balance Modeling! The Shodor Education Foundation, Inc,

$\begin{array}{ccccc}1998 . & \text { Retrieved } & \text { March } & 18, & 2020, \\ \text { http://www.shodor.org/master/environmental/general/energy/application.html }\end{array}$

from

WILLIAMS, William F., ed. (2000). Encyclopedia of Pseudoscience. Fitzroy Dearborn. ISBN 9781579582074. 